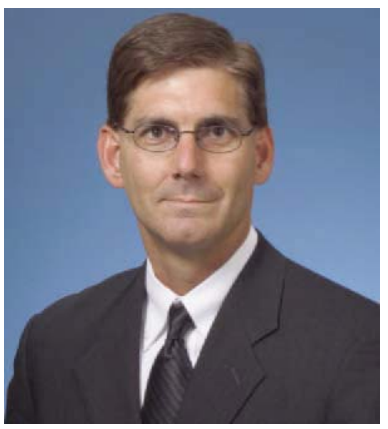

\section{Conference Papers and Journal Papers}

I will never forget my first conference paper. It was in New Orleans and the audience was not large, but I was terrified. My first slide was presented and it was everything I could do just to introduce myself and acknowledge my coauthors. I remember thinking that I knew I was speaking, but the words were just not coming out! Speaking from a state of panic resulted in a very confusing research paper. The whole "pretend the audience is in their underwear" just did not work for me. Afterwards, my professor gave me some of the best advice that I use to this day. If you are going to take 20 minutes of an audience's time (100 people make a collective 33 hours, or almost a work week), make sure they get an interesting presentation. Do not waste their time.

My paper ended up in a conference proceedings. Conferences are intended to be a forum where you can share your work as well as learn what others are working on. Conference papers typically are not polished archival products, but a snapshot in time and a means to communicate and network with your colleagues in your research area. Some conference papers are works-in-progress where the research is not fully completed. Journals, on the other hand, are a means to take research that is both significant and original and archive the work in a clear and concise way. One can recreate an experiment from a well-written journal paper. One can perform a technical analysis with a well-written journal paper. Since conference papers and journal papers serve two different purposes, one might assume that a conference paper could not satisfy the requirements (significance and originality) of a journal paper. However, this is not so black and white, and I have been involved with numerous discussions on whether submitting a conference proceedings paper to Optical Engineering is acceptable. In the scientific community, there are a number of editors and publishers who believe that submitting a conference paper to a journal constitutes dual submission or self-plagiarism. I do not ascribe to this view and want to set the record straight in this regard for Optical Engineering.

Most conference papers need to be expanded upon or, at least, cleaned up prior to submission to Optical Engineering. In some cases the research needs to be completed and the results and conclusions validated before the work is suitable for submission to a journal. However, in a few cases, the conference paper is an outstanding piece of research, written to journal standards. In this case, it is fine to submit the conference paper, or a version very similar to the conference paper, to Optical Engineering. Usually the peer-review process requires some modification anyway before the paper is accepted and published. However, even if the paper is accepted without changes (a fairly unusual circumstance), it becomes an archival peer-reviewed paper in Optical Engineering, which in itself is a differentiator from the proceedings version. This is acceptable as long as I am editor. In fact, I have been monitoring the "Top Ten Downloads" from the proceedings papers on the SPIE Digital Library, and I personally invite those authors with interesting and relevant conference papers to submit them, or a derivative of them, to Optical Engineering. If you submit a conference paper to Optical Engineering, please make sure it is journal quality so that our valuable peer-review process is not overburdened.

In an ironic twist, about five years after I gave my first conference paper, my wife at the time (a medical doctor) prescribed me a beta blocker that was intended to block the overgeneration of adrenaline. It was supposed to help me stay calm. It worked and I gave the most boring conference paper ever. It ruined my talk and I was so dull that I never took a beta blocker again. I still get butterflies before I give a paper, and I embrace them now. It provides me with a little boost and pep that makes my talks exciting and interesting because I want the audience to enjoy the experience that I enjoy: my research.

Ronald G. Driggers Editor 